American Journal of Pediatrics
2020; 6(4): $481-487$
http://www.sciencepublishinggroup.com/j/ajp
doi: 10.11648 /j.ajp.20200604.26
ISSN: $2472-0887$ (Print); ISSN: $2472-0909$ (Online)

\title{
Clinical Presentation and Complications of Different Congenital Heart Disease in Children
}

\author{
Kuntal Roy1, *, Md. Humayun Shahed ${ }^{2}$, Kaushik Roy ${ }^{3}$, Quazi Sahely $\operatorname{Sarah}^{4}$, \\ Nandita Sur Chowdhury ${ }^{5}$ \\ ${ }^{1}$ Department of Pediatrics, Anwer Khan Modern Medical College, Dhaka, Bangladesh \\ ${ }^{2}$ Sadar Hospital, Jhenaidah, Khulna, Bangladesh \\ ${ }^{3}$ Cardiovascular \& Thorasic Surgery, National Institute of Cardiovascular Disease \& Hospital, Dhaka, Bangladesh \\ ${ }^{4}$ Department of Pharmacology, Jashore Medical College, Jashore, Bangladesh \\ ${ }^{5}$ Department of Anaesthesia, Analgesia \& Intencive Care Medicine, Rajshahi Medical College, Rajshahi, Bangladesh
}

\section{Email address:}

ripon318@yahoo.com (K. Roy)

${ }^{*}$ Corresponding author

\section{To cite this article:}

Kuntal Roy, Md. Humayun Shahed, Kaushik Roy, Quazi Sahely Sarah, Nandita Sur Chowdhury. Clinical Presentation and Complications of Different Congenital Heart Disease in Children. American Journal of Pediatrics. Vol. 6, No. 4, 2020, pp. 481-487.

doi: 10.11648/j.ajp.20200604.26

Received: June 14, 2020; Accepted: October 10, 2020; Published: December 16, 2020

\begin{abstract}
The clinical presentation of congenital heart disease varies according to the type and severity of the defect. Aim of the study: The aim of this study is to observe the clinical presentation and complications of different congenital heart disease. Material \& Methods: It was a hospital based Cross-sectional study carried out prospectively in the department of pediatrics of Rajshahi medical college \& hospital in from July 2011 to December 2011. The study population was all the children up to 12 years of age admitted in three pediatric units of this hospital during the study period. History included the presenting complaints of the patient's e.g. breathlessness, cough, palpitation, undue fatigability, bluish coloration or lips, tongue and extremities, history suggestive of cyanotic spell, feeding problem, poor weight gain, recurrent chest infection etc. Onset of symptoms and duration were noted. Chest X-ray reports were done by radiologists, ECG reports and echocardiography were done by cardiologists of RMCH. Among the 147 clinically suspected cases congenital heart disease was confirmed in 110 cases by echocardiography. Results: Total 110 patients with different types of congenital heart disease were included in this study. Male: female ratio were 2:1. the commonest lesion was VSD present in 39.1 (\%) patients and single ventricle with single A-V canal defect in $0.9(\%)$. Rest patients had multiple lesions. The commonest presentation was recurrent chest infection which present in $69.1(\%)$ of patients. The commonest physical finding was anemia, present in $72.7(\%)$ of patients. Among 110 patients, 101 presented with different complications. Heart failure was present in total 15 cases, among them 40 (\%) of VSD, 33.3 (\%) of PDA and $26.7(\%)$ of multiple lesions patients presented with heart failure. Growth failure was observed in total 23 cases, among them 13 (\%) of VSD, 21.7 (\%) of ASD, 43.5 (\%) of TOF, 8.7 (\%) of PDA and 13.1 (\%) of other patients presented with growth failure. Pneumonia was noted in $54.3(\%)$ of VSD, $22.9(\%)$ of ASD, $17.1(\%)$ of PDA and $5.7(\%)$ of other patients. Recurrent chest infection was noted in $70(\%)$ of VSD and $30(\%)$ of PDA patients. Pneumonia with heart failure was noted in $54.3(\%)$ of VSD, $22.9(\%)$ of ASD, 17.1 (\%) of PDA and $5.7(\%)$ of other patients. Cerebral abscess occurred only in TOF cases. Conclusion: Fast breathing, chest indrawing, cough, poor weight gain, feeding problems, anemia, cyanosis, clubbing, easy fatigability, recurrent chest infection and murmur detected in routine cardiac examination
\end{abstract}

Keywords: Congenital Heart Disease, Clinical Presentation, Complications, Atrial Septal Defect, VSD, PDA, Pulmonary Stenosis 


\section{Introduction}

Congenital heart disease as a whole occurs with equal frequency in male and females but some lesions such as transposition of great vessels and left sided obstructive lesions are slightly more common in boys whereas atrial septal defect, VSD, PDA and pulmonary stenosis are more common in girls. [1] The clinical presentation of congenital heart disease varies according to the type and severity of the defect. $^{2}$ In neonatal period the presenting features of congenital heart disease are cyanosis (with or without respiratory distress), heart failure (with or without cyanosis), collapse \& an abnormal clinical sign detected on routine examination (e.g. absent femoral pulse or a heart murmur). $[2,3]$ In infancy and childhood the usual presenting features are cyanosis, digital clubbing, murmur, syncope, frequent respiratory tract infection, squatting, heart failure, arrhythmia and failure to thrive. ${ }^{3}$ The adolescent present with heart failure, murmur, arrhythmia, cyanosis, hypertension \& late consequences of previous cardiac surgery (e.g., arrhythmia, heart failure). [3] In over $90 \%$ of instances the cause of CHD is unknown. However, multifactorial inheritance with both genetic and environmental inputs is suspected. [1] Here, there is combined action of environmental influence and two or more mutant genes having additive effect. The genetic component exerts a dosage effect- the greater the number of inherited deleterious genes, the more severe the expression of the disease. Because environmental factors significantly influence the expression of these genetic disorders, the term polygenic inheritance is misleading. [4] There is two to tenfold increase in the incidence of congenital heart disease in sibling of an affected patient or children of an affected parent, pointing to genetic influences. On the other hand, monozygotic twin has only a $10 \%$ concordance for ventricular septa) defects. [5] There is well-defined sex preponderance for certain specific defects. Overall, males are more often involved. Thus, there are many kinds of genetic influence, but the twin studies make clear that environmental influences although rarely identifiable, must also contribute. Clinical presentation of congenital heart disease differs conferring to the category and severity of the defect. [6] At present the offering feature of congenital heart disease are cyanosis, heart failure with or without cyanosis, collapse, an abnormal clinical sign detected on routine examination. [6] In early stages and childhood the typical symptoms are cyanosis, digital clubbing, murmur, syncope, squatting, heart failure, arrhythmia, failure to thrive. [7] The teenage and grownups faces heart failure, murmur, arrhythmia, cyanosis, hypertension, late consequences of previous cardiac surgery. [7] By way of a mutual congenital anomaly, CHD not only subsidize to a noteworthy morbidity and mortality but also causes a great psychological stress and economic load to the whole family. Yet, if the complications are familiar at earlier age, the coincidental of long-term difficulties are less and the outcome is healthier. In place of a result of enhanced medical and surgical management, more children with CHD are enduring into adolescence and adulthood. [8] Therefore, there is a necessity for an improved responsiveness amongst general physicians and cardiologists of the problem modeled by these individuals. Excluding a few scattered annotations, the incidence and detail clinical profile of CHD in Bangladeshi children are not well recognized. This study was commenced to find out the pattern and clinical presentation and complications of congenital heart disease among the admitted children in Rajshahi Medical College Hospital. It may help to detect and treat congenital heart disease at an earlier age and thus give the affected children and their parents hope of a better life.

\section{Methodology and Materials}

It was a hospital based Cross-sectional study carried out prospectively in the department of pediatrics of Rajshahi medical college \& hospital in from July 2011 to December 2011. The study population was all the children up to 12 years of age admitted in three pediatric units of this hospital during the study period. In all cases detail history was obtained from the parents. History included the presenting complaints of the patient's e.g. breathlessness, cough, palpitation, undue fatigability, bluish coloration or lips, tongue and extremities, history suggestive of cyanotic spell, feeding problem, poor weight gain, recurrent chest infection etc. Onset of symptoms and duration were noted. Chest $\mathrm{X}$ ray reports were done by radiologists, ECG reports and echocardiography were done by cardiologists of $\mathrm{RMCH}$. Among the 147 clinically suspected cases congenital heart disease was confirmed in 110 cases by echocardiography. After confirming the diagnosis data was noted in a preformed data sheet.

1) Inclusion Criteria

a) All cases of clinically diagnosed congenital heart disease admitted into all pediatric units of Rajshahi Medical College Hospital, Rajshahi.

2) Exclusion Criteria

b) The patients who are critically ill and age more than 12 years will be excluded from the study.

\section{Results}

Total 110 patients with different types of congenital heart disease were included in this study. Among them male patient is $67 \%$ and female is $33 \%$. So male: female ratio is $2: 1$. It is evident from Table 1 that the commonest lesion was VSD present in $39.1(\%)$ patients followed by PDA in $17.3(\%)$, TOF in $15.5(\%)$, ASD in $11.8(\%)$, A-V canal defect in 0.9 $(\%)$, PS in $1.8(\%)$, COA in $1.8(\%)$, TGA in $1.8(\%)$ and single ventricle with single $\mathrm{A}-\mathrm{V}$ canal defect in $0.9(\%)$. Rest patients had multiple lesions. Table 2 shows detailed clinical presentation of CHD cases. In the present series, among 110 patients of CHD, the commonest presentation was recurrent chest infection which present in 69.1 (\%) of patients. Then in order of frequency other presentations were poor weight gain in $51.8(\%)$, respiratory distress in $46.4(\%)$, cough in 44.5 $(\%)$, fever in $44.5(\%)$, feeding problem in $36.4(\%)$, dyspnea 
on exertion in $29.1(\%)$, hyper cyanotic spell in $23.6(\%)$ and convulsion in $4.8(\%)$ patients. It is evident from Table 3 that some important physical findings in CHD patients. Here the commonest physical finding was anemia, present in $72.7(\%)$ of patients. Other findings were tachycardia in 47.3 (\%), fast breathing in $47.3(\%)$, cyanosis in $27.3(\%)$, clubbing in 15.5 (\%), edema in $10.9(\%)$, conjunctival congestion in $15.5(\%)$, enlarged tender liver in $15.5(\%)$, hypertension in $27.3(\%)$, chest indrawing in $31.8(\%)$, crepitation in $47.3(\%)$ and rhonchi in 30.9 (\%) patients. Table 4 shows the cardiac findings in CHD cases. Thrill was mostly present in $60.5(\%)$ of VSD cases, in $42.1(\%)$ of PDA, in $50(\%)$ of A-V canal defect and $10(\%)$ of multiple lesions patients. Palpable P2 was present in $27.9(\%)$ of VSD cases, $15(\%)$ of TOF, 50 (\%) of PS and $30(\%)$ of multiple lesions patients. Left parasternal heave was found in $25.6(\%)$ of VSD cases, 15.6 (\%) of ASD, $88.2(\%)$ of TOF, 50 (\%) of PS and $40(\%)$ of multiple lesions patients. Wide and fixed splitting S2 was present in $84.6(\%)$ cases of ASD and $10(\%)$ of multiple lesions. Single S2 was found in all $(100 \%)$ cases of PS, 30 (\%) of multiple lesions and $88.2(\%)$ cases of TOF. Table 5 shows important radiological findings (of X-ray chest) in different CHD patients. Cardiomegaly was present in 5.3\% of PDA, $50 \%$ of COA, $50 \%$ of PS and $20 \%$ of multiple lesions cases. Plethoric lung field with cardiomegaly \& consolidation was observed in $10 \%$ of VSD \& $21 \%$ of PDA cases. Cardiomegaly with consolidation was observed in $11.6 \%$ of VSD \& $15.6 \%$ of ASD cases. Cardiomegaly with plethoric lung field was observed in $46.2 \%$ of VSD, $63.2 \%$ of PDA, $76.9 \%$ of ASD, $50 \%$ of AV canal defect \& TGA cases. Boot shape heart with oligamic lung was observed in $88.2 \%$ of TOF patients. Oligaemic lung was noted in $11.8 \%$ of TOF and $20 \%$ of multiple lesions cases. Pulmonary opacity/consolidation was found in $4.7 \%$ of VSD cases. Table 6 shows detailed ECG findings in CHD patients. RVH with RAD was noted in $4.7 \%$ of VSD cases, in $30.8 \%$ of ASD cases, in $82.4 \%$ of TOF, in $100 \%$ of PS and $50 \%$ of other CHD patients. LVH with LAD was found in $46.5 \%$ of VSD cases, in $38.8 \%$ of ASD, in $63.9 \%$ of PDA and in $50 \%$ of $\mathrm{COA}$ patients. $\mathrm{RVH}+\mathrm{LVH}+$ Tall $\mathrm{P}$ (P pulmonale) was present in $7 \%$ of VSD cases, $7.7 \%$ of ASD, $50 \%$ of AV canal defect and TGA patients. In this study $37.2 \%$ of VSD, $15.4 \%$ of ASD, $26.3 \%$ of PDA, $50 \%$ of PS and $50 \%$ of multiple lesion patients had normal ECG tracing. Table 7 shows among 110 patients, left ventricular and atrial dimension was increased in most cases of VSD, PDA and COA. Right atrial and right ventricular dimension was increased in most cases of ASD, PS, single ventricle, TOF and a few cases of VSD \& other
CHD. Narrow RVOT and Overriding of aorta was present in all cases of TOF. Table 8 shows among 43 VSD patients 53.5 (\%) were peri- membranous, $34.9(\%)$ were muscular and $11.6(\%)$ were supracristal variety. Among 43 VSD patients $11.6(\%)$ were small, $30.2(\%)$ were medium and $53.5(\%)$ were large variety. Table 9 shows among 13 ASD patients 7.7 (\%) were osteum primum, 92.3 (\%) were osteum secondum variety. Table 10 shows complications of different CHD patients. Among 110 patients, 101 presented with different complication. Heart failure was present in total 15 cases, among them, 40 (\%) of VSD, 33.3 (\%) of PDA and 26.7 (\%) of multiple lesions patients presented with heart failure. Growth failure was observed in total 23 cases, among them, $13(\%)$ of VSD, 21.7 (\%) of ASD, 43.5 (\%) of TOF, $8.7(\%)$ of PDA and $13.1(\%)$ of other patients presented with growth failure. Pneumonia was noted in $54.3(\%)$ of VSD, $22.9(\%)$ of ASD, $17.1(\%)$ of PDA and $5.7(\%)$ of other patients. Recurrent chest infection was noted in 70 (\%) of VSD and 30 (\%) of PDA patients. Pneumonia with heart failure was noted in $54.3(\%)$ of VSD, $22.9(\%)$ of ASD, $17.1(\%)$ of PDA and $5.7(\%)$ of other patients. Cerebral abscess occurred only in TOF cases.

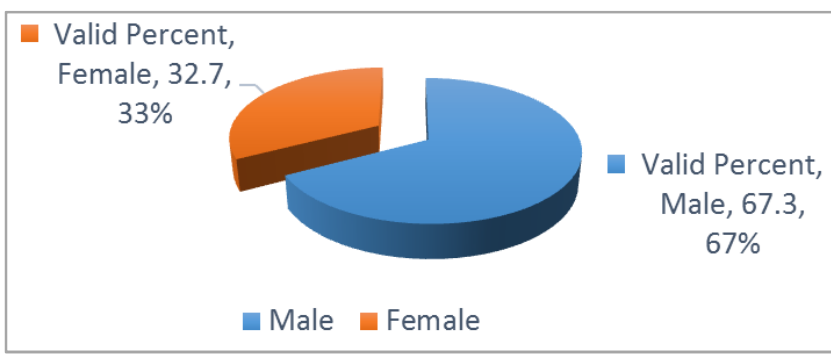

Figure 1. Sex distribution of different congenital heart disease (n-110).

Table 1. Types of congenital heart disease in all patients from birth to 12 years of age $(n-110)$.

\begin{tabular}{lll}
\hline Types of Lesion & No. of Patient & Percentage \\
\hline VSD & 43 & 39.1 \\
ASD & 13 & 11.8 \\
TOF & 17 & 15.5 \\
PDA & 19 & 17.3 \\
A-V canal & 1 & 0.9 \\
PS & 2 & 1.8 \\
TGA & 2 & 1.8 \\
COA & 2 & 1.8 \\
Multiple lesion & 10 & 9.1 \\
Single ventricle with single A-V & 1 & 0.9 \\
canal defect & 110 & 100.0 \\
Total & & \\
\hline
\end{tabular}

Table 2. Clinical presentation of congenital heart disease (n-110).

\begin{tabular}{lll}
\hline Symptoms & No. of cases & Percentage \\
\hline Respiratory distress & 51 & $46.4 \%$ \\
Fever & 49 & $44.5 \%$ \\
Cough & 49 & $44.5 \%$ \\
Poor weight gain & 57 & $51.8 \%$ \\
Recurrent chest infection & 76 & $69.1 \%$ \\
Feeding problem & 40 & $36.4 \%$ \\
Dyspnea on exertion & 32 & $29.1 \%$ \\
\hline
\end{tabular}




\begin{tabular}{lll}
\hline Symptoms & No. of cases & Percentage \\
\hline Hyper cyanotic spell & 26 & $23.6 \%$ \\
Convulsion & 2 & $4.8 \%$ \\
\hline
\end{tabular}

Table 3. Important physical findings in CHD (n-110).

\begin{tabular}{lll}
\hline Physical finding & No. of cases & Percentage \\
\hline Cyanosis & 30 & 27.3 \\
Clubbing & 17 & 15.5 \\
Edema & 12 & 10.9 \\
Anemia & 80 & 72.7 \\
Hypertension & 20 & 27.3 \\
Conjunctival congestion & 17 & 15.5 \\
Tachycardia & 52 & 47.3 \\
Enlarged tender liver & 17 & 15.5 \\
Fast breathing & 50 & 45.9 \\
Chest indrawing & 35 & 31.8 \\
Crepitation & 52 & 47.3 \\
Rhonchi & 34 & 30.9 \\
\hline
\end{tabular}

Table 4. Important cardiac findings in CHD Patients (n-110).

\begin{tabular}{llllll}
\hline Types of lesion & Thrill n (\%) & Palpable P2 n (\%) & Parasternal Heave n (\%) & Wide \& Fixed splitting S2 n (\%) & Single S2 n (\%) \\
\hline VSD & $26(60.5 \%)$ & $12(27.9 \%)$ & $11(25.6 \%)$ & $0(0 \%)$ & $0(0 \%)$ \\
ASD & $0(0 \%)$ & $0(0 \%)$ & $2(15.6 \%)$ & $11(84.6 \%)$ & $0(0 \%)$ \\
TOF & $0(0 \%)$ & $15(88.2 \%)$ & $15(88.2 \%)$ & $0(0 \%)$ & $15(88.2 \%)$ \\
PDA & $8(42.1 \%)$ & $0(0 \%)$ & $0(0 \%)$ & $0(0 \%)$ & $0(0 \%)$ \\
A-V canal defect & $1(50 \%)$ & $0(0 \%)$ & $0(0 \%)$ & $0(0 \%)$ & $0(0 \%)$ \\
PS & $0(0 \%)$ & $1(50 \%)$ & $1(50 \%)$ & $0(0 \%)$ & $2(100 \%)$ \\
TGA & $0(0 \%)$ & $0(0 \%)$ & $0(0 \%)$ & $0(0 \%)$ & $0(0 \%)$ \\
COA & $0(0 \%)$ & $0(0 \%)$ & $0(0 \%)$ & $0(0 \%)$ & $0(0 \%)$ \\
Multiple lesion & $1(10 \%)$ & $3(30 \%)$ & $4(40 \%)$ & $1(10 \%)$ & $3(30 \%)$ \\
\hline
\end{tabular}

Note: Parenthesis indicate percentage in respect of total no, of individual defect.

Table 5. Important radiological findings (of $x$-ray chest) in CHD patients (n-110).

\begin{tabular}{|c|c|c|c|c|c|c|c|c|c|c|}
\hline \multirow[b]{2}{*}{ Lesion } & \multicolumn{9}{|c|}{ X-ray chest } & \multirow[b]{2}{*}{ Total } \\
\hline & Normal & $\begin{array}{l}\text { Cardio- } \\
\text { megally }\end{array}$ & $\begin{array}{l}\text { Cardiome- } \\
\text { gally with } \\
\text { Plethoric } \\
\text { lung }\end{array}$ & $\begin{array}{l}\text { Cardiomegally } \\
\text { with } \\
\text { consolidation }\end{array}$ & $\begin{array}{l}\text { Plethoric lung } \\
\text { with } \\
\text { consolidation }\end{array}$ & $\begin{array}{l}\text { Boot shape } \\
\text { heart with } \\
\text { oligamic } \\
\text { lung }\end{array}$ & $\begin{array}{l}\text { Oligamic } \\
\text { lung }\end{array}$ & $\begin{array}{l}\text { Cardiomegally } \\
\text { with } \\
\text { consolidation } \\
\text { with plethoric } \\
\text { lung }\end{array}$ & Consolidation & \\
\hline VSD & $1(2.3 \%)$ & & $20(46.2 \%)$ & $5(11.6 \%)$ & $5(11.6 \%)$ & & & $10(23 \%)$ & $2(4.7 \%)$ & $43(100 \%)$ \\
\hline ASD & & & $10(76.9 \%)$ & $1(7.7 \%)$ & $2(15.4 \%)$ & & & & & $13(100 \%)$ \\
\hline TOF & & & & & & $15(88.2 \%)$ & $2(11.8 \%)$ & & & $17(100 \%)$ \\
\hline PDA & $2(10.3 \%)$ & $1(5.3 \%)$ & $12(63.2 \%)$ & & & & & $4(21.1 \%)$ & & $19(100 \%)$ \\
\hline A-V canal & $1(50.0 \%)$ & & $1(50 \%)$ & & & & & & & $2(100 \%)$ \\
\hline PS & $1(50.0 \%)$ & $1(50 \%)$ & & & & & & & & $2(100 \%)$ \\
\hline TGA & $1(50.0 \%)$ & & $1(50 \%)$ & & & & & & & $2(100 \%)$ \\
\hline $\mathrm{COA}$ & $1(50.0 \%)$ & $1(50 \%)$ & & & & & & & & $2(100 \%)$ \\
\hline $\begin{array}{l}\text { Multiple } \\
\text { lesion }\end{array}$ & $5(50.0 \%)$ & $2(20 \%)$ & $1(10 \%)$ & & & & $2(20 \%)$ & & & $10(100 \%)$ \\
\hline Total & $12(14 \%)$ & $5(4.5 \%)$ & $44(40 \%)$ & $6(5.5 \%)$ & $7(6.4 \%)$ & $15(13.6 \%)$ & $4(5.5 \%)$ & $14(12.7 \%)$ & $2(1.8 \%)$ & $110(100 \%)$ \\
\hline
\end{tabular}

Note: Parenthesis indicate percentage in respect of total no. of individual defect.

Table 6. ECG findings in CHD patients (n-110).

\begin{tabular}{llllllll}
\hline \multirow{2}{*}{ Lesion } & \multicolumn{2}{l}{ Electrocardiogram } & & & & \\
\cline { 2 - 7 } & Normal & RVH & RVH+RAD & LVH & LVH+LAD & RVH+LVH+P-Pulmonale & Total \\
\hline VSD & $16(37.2 \%)$ & $0(0 \%)$ & $2(4.7 \%)$ & $2(4.7 \%)$ & $20(46.5 \%)$ & $3(7 \%)$ & $43(100 \%)$ \\
ASD & $2(15.4 \%)$ & $0(0 \%)$ & $4(30.8 \%)$ & $1(7.7 \%)$ & $5(38.8 \%)$ & $1(7.7 \%)$ & $13(100 \%)$ \\
TOF & $0(0 \%)$ & $2(11.8 \%)$ & $14(82.4 \%)$ & $0(0 \%)$ & $1(5.9 \%)$ & $0(0 \%)$ & $17(100 \%)$ \\
PDA & $5(26.3 \%)$ & $0(0 \%)$ & $1(5.3 \%)$ & $1(5.3 \%)$ & $12(63.9 \%)$ & $0(0 \%)$ & $19(100 \%)$ \\
A-V canal & $1(50 \%)$ & $0(0 \%)$ & $0(0 \%)$ & $0(0 \%)$ & $0(0 \%)$ & $1(50 \%)$ & $2(100 \%)$ \\
PS & $0(0 \%)$ & $0(0 \%)$ & $2(100 \%)$ & $0(0 \%)$ & $0(0 \%)$ & $0(0 \%)$ & $2(100 \%)$ \\
TGA & $1(50 \%)$ & $0(0 \%)$ & $0(0 \%)$ & $0(0 \%)$ & $0(0 \%)$ & $1(50 \%)$ & $2(100 \%)$ \\
\hline
\end{tabular}




\begin{tabular}{llllllll}
\hline \multirow{2}{*}{ Lesion } & \multicolumn{2}{l}{ Electrocardiogram } & & & & \\
\cline { 2 - 7 } & Normal & RVH & RVH+RAD & LVH & LVH+LAD & RVH+LVH+P-Pulmonale & Total \\
\hline COA & $1(50 \%)$ & $0(0 \%)$ & $0(0 \%)$ & $0(0 \%)$ & $1(50 \%)$ & $0(0 \%)$ & $2(100 \%)$ \\
Multiple lesion & $5(50 \%)$ & $0(0 \%)$ & $5(50 \%)$ & $0(0 \%)$ & $0(0 \%)$ & $0(0 \%)$ & $10(100 \%)$ \\
Total & $31(28.2 \%)$ & $2(1.8 \%)$ & $28(25.5 \%)$ & $4(3.6 \%)$ & $37(35.6 \%)$ & $6(5.5 \%)$ & $110(100 \%$ \\
\hline
\end{tabular}

Note: Parenthesis indicate percentage in respect of total no. of individual defect.

Table 7. Echocardiographic findings of patients under study (n-110).

\begin{tabular}{|c|c|c|c|c|c|c|c|c|c|}
\hline \multirow{2}{*}{ Finding } & \multicolumn{9}{|c|}{ Ecocardiography } \\
\hline & VSD & ASD & TOF & PDA & A-V canal & PS & TGA & $\mathrm{COA}$ & Multiple lesion \\
\hline \multirow{2}{*}{ Right venous hypertrophy } & 0 & 0 & 2 & 0 & 0 & 0 & 0 & 0 & 0 \\
\hline & $.0 \%$ & $.0 \%$ & $100.0 \%$ & $.0 \%$ & $.0 \%$ & $.0 \%$ & $.0 \%$ & $.0 \%$ & $.0 \%$ \\
\hline \multirow{2}{*}{$\mathrm{RAD}+\mathrm{RVH}$} & 2 & 4 & 14 & 1 & 0 & 2 & 0 & 0 & 5 \\
\hline & $7.1 \%$ & $14.3 \%$ & $50.0 \%$ & $3.6 \%$ & $.0 \%$ & $7.1 \%$ & $.0 \%$ & $.0 \%$ & $17.9 \%$ \\
\hline \multirow{2}{*}{ Left venus hypertrophy } & 2 & 1 & 0 & 1 & 0 & 0 & 0 & 0 & 0 \\
\hline & $50.0 \%$ & $25.0 \%$ & $.0 \%$ & $25.0 \%$ & $.0 \%$ & $.0 \%$ & $.0 \%$ & $.0 \%$ & $.0 \%$ \\
\hline \multirow{2}{*}{$\mathrm{LAD}+\mathrm{LVH}$} & 20 & 4 & 1 & 11 & 0 & 0 & 0 & 1 & 0 \\
\hline & $54.1 \%$ & $10.8 \%$ & $2.7 \%$ & $29.7 \%$ & $.0 \%$ & $.0 \%$ & $.0 \%$ & $2.7 \%$ & $.0 \%$ \\
\hline \multirow{2}{*}{ Narrow RVOT } & 0 & 0 & 17 & 0 & 0 & 0 & 0 & 0 & 0 \\
\hline & $.0 \%$ & $.0 \%$ & $100.0 \%$ & $.0 \%$ & $.0 \%$ & $.0 \%$ & $.0 \%$ & $.0 \%$ & $.0 \%$ \\
\hline \multirow{2}{*}{ Overriding of aorta } & 0 & 0 & & 0 & 0 & 0 & 0 & 0 & 0 \\
\hline & $.0 \%$ & $.0 \%$ & $100.0 \%$ & $.0 \%$ & $.0 \%$ & $.0 \%$ & $.0 \%$ & $.0 \%$ & $.0 \%$ \\
\hline
\end{tabular}

Note: Parenthesis indicate percentage in respect of total no. of individual defect.

Table 8. Echocardiographic findings of VSD patients under study (n-43).

\begin{tabular}{lll}
\hline Types of VSD & Frequency & Percentage \\
\hline Peri membranous & 23 & 53.5 \\
Muscular & 15 & 34.9 \\
Supracrystal & 5 & 11.6 \\
Small & 7 & 16.3 \\
Medium & 13 & 30.2 \\
Large & 23 & 53.5 \\
\hline
\end{tabular}

Table 9. Echocardiographic findings of ASD patients under study (n-13).

\begin{tabular}{lll}
\hline Types of ASD & Frequency & Percentage \\
\hline Osteum primum & 1 & $7.7 \%$ \\
Osteum secundum & 12 & $92.3 \%$ \\
Total & 13 & $100.0 \%$ \\
\hline
\end{tabular}

Table 10. Complications of different CHD (n-110).

\begin{tabular}{|c|c|c|c|c|c|c|c|c|c|}
\hline \multirow[t]{2}{*}{ Complication } & \multicolumn{8}{|c|}{ Types of Lesion } & \multirow{2}{*}{ Total } \\
\hline & VSD & ASD & TOF & PDA & A-V Canal & PS & COA & Multiple Lesion & \\
\hline Heart failure & $6(40 \%)$ & $0(0 \%)$ & $0(0 \%)$ & $5(33.3 \%)$ & $0(0 \%)$ & $0(0 \%)$ & $0(0 \%)$ & $4(26.7 \%)$ & $15(100 \%)$ \\
\hline Pneumonia & $19(54.3 \%)$ & $8(22.9 \%)$ & $0(0 \%)$ & $6(17.1 \%)$ & $0(0 \%)$ & $1(2.9 \%)$ & $0(0 \%)$ & $1(2.9 \%)$ & $35(100 \%)$ \\
\hline Growth failure & $3(13 \%)$ & $5(21.7 \%)$ & $10(43.5 \%)$ & $2(8.7 \%)$ & $1(4.3 \%)$ & $1(4.3 \%)$ & $1(4.3 \%)$ & $0(0 \%)$ & $23(100 \%)$ \\
\hline $\begin{array}{l}\text { Recurrent respiratory tract } \\
\text { infection }\end{array}$ & $8(57.1 \%)$ & $0(0 \%)$ & $0(0 \%)$ & $3(21.4 \%)$ & $1(7.1 \%)$ & $0(0 \%)$ & $1(7.1 \%)$ & $1(7.1 \%)$ & $14(100 \%)$ \\
\hline Cerebral abscess & $0(0 \%)$ & $0(0 \%)$ & $4(100 \%)$ & $0(0 \%)$ & $0(0 \%)$ & $0(0 \%)$ & $0(0 \%)$ & $0(0 \%)$ & $4(100 \%)$ \\
\hline Pneumonia with Heart failure & $7(70 \%)$ & $0(0 \%)$ & $0(0 \%)$ & $3(30 \%)$ & $0(0 \%)$ & $0(0 \%)$ & $0(0 \%)$ & $0(0 \%)$ & $10(100 \%)$ \\
\hline Total & $43(42.6 \%)$ & $13(12.9 \%)$ & $14(13.9 \%)$ & $19(18.8 \%)$ & $2(2 \%)$ & $2(2 \%)$ & $2(2 \%)$ & $6(5.9 \%)$ & $101(100 \%)$ \\
\hline
\end{tabular}

Note: Parentesis indicate percentage in respect of total no. of individual defect.

\section{Discussion}

This prospective study was conducted in the department of pediatrics of Rajshahi medical college \& hospital from July, 2011 to December, 2011. Babies from birth to children up to 12 years of age were included in this study. The aim of this study was to know the clinical pattern of congenital heart disease in this hospital. In this study the commonest type of
Congenital heart disease was ventricular septal defect. This correlates with many studies. [9-13] But this differs from Rahman et al, Siddique et al and Fatema et al [14-18]. They found ASD the commonest lesion. This difference in observation might be due to that Rahman et al and Siddique et al included many adult patients in their study. [16-18] A significant proportion of VSD close spontaneously before adulthood and some untreated patients with large VSD die in childhood from heart failure. On the other hand, ASD 
patients may remain asymptomatic in childhood and are diagnosed for the first time when they are adult. The study subject of Fatema et al were all newborn and many small sized VSD and most of the child with TOF may not manifest by that time. $[14,15]$ However all these studies found TOF as the commonest cyanotic congenital heart disease [10-20]. This finding is quite similar to the current study. In this study male and female ratio was 2:1, of which males are predominant in ASD, TOF, COA, TGA, multiple lesions, PS, $\mathrm{A}-\mathrm{V}$ canal defect and single ventricle with single AV canal defect whereas females were more frequently noted in VSD and PDA. This gender distribution correlates partially with the observation of Mollah et al, Hussain et al and Rao \& Reddy. [21-23] Of the different clinical features, fast breathing, chest indrawing, cough, poor weight gain, feeding problems, anaemia, cyanosis, clubbing - were the major ones and this observation were correlated well with other studies in Bangladesh [21], India [24, 25] and western countries [26, 27]. In this study we found a significant number of ASD cases were asymptomatic and admitted in hospital for some other disease condition. These cases were diagnosed incidentally during routine systemic examination. A small ASD can remain asymptomatic throughout life. [28] Cardiac findings revealed murmur with or without thrill were the most frequently observed feature. Pansystolic murmur was found in all $(100 \%)$ cases of VSD, similar with Keith [29]. Ejection systolic murmur was present in all $(100 \%)$ cases of TOF; consistent with the findings of Naik et al [30] and also $76.9 \%$ cases of ASD; consistent with Siddique et al [17], Continues machinery murmur was found in $100 \%$ cases of PDA; similar to Siddique et al. [17] In this study, most frequent associated disease with CHD was pneumonia present in $35 \%$ cases and commonly observed complications were heart failure $15 \%$ and growth failure $23 \%$. Fast breathing, chest indrawing, cough, poor weight gain, feeding problems, anemia, cyanosis, clubbing, easy fatigability, recurrent chest infection and murmur detected in routine cardiac examination. Features of heart failure are common mode of presentation of congenital heart disease. Without correction of congenital heart defect outcome of the patients are not satisfactory.

\section{Limitations of the study}

This cross-sectional study was conducted in a single community. Limitations of this study were this hospital lacks facilities for curative treatment of different congenital heart disease and this study was done in a selected group of patients. So, an extensive study with large sample size and longer period of time should be conducted to get a real picture of the problem; so that cases can be recognized earlier and prompt action can be undertaken.

\section{Conclusion and Recommendations}

All newborn babies should be examined thoroughly for any evidence of CHD and a follow up examination should be advised in late infancy. Children with undue fatigability, recurrent chest infection, failure to thrive should give due attention to exclude CHD.

\section{References}

[1] Bernstein D. Epidemiology and Genetic Basis of Congenital heart disease. In Behrman RE, Kligman RM, Jenson HB, editors. Nelson textbook of Pediatrics. 18th ed. Philadelphia: Saunders, 2008; 1878-1881.

[2] Kitchiner D J. Clinical assessment of heart disease, the neonate with a congenital heart disease. In: Mclntosh N, Helms PJ, Smyth RL, editors. Forfer \& Arneil's Textbook of Pediatrics. 7th ed. Edinburgh: Churchill Livingstone, 2008; 743-799.

[3] Bloomfield P, Bradbury A, Grubb NR, Newby DE. Congenital heart disease. In: Boon NA, Collede NR, Walker BR, editors. Davidson's Principle and Practice of Medicine. 21st ed. Edinburgh: Churchill Livingstone, 2010: p- 628-635.

[4] Schoen FJ. Congenital heart disease, In: Cortan RS, Kumar V, Robins SL, editors. Robins Pathologic Basis of Disease.7th ed. Philadelphia: W. B. Saunders Company, 2005; 564-571.

[5] Newman TB. Etiology of Ventricular septal defects: An epidemiologic approach. Pediatrics 1985; 76: 741.

[6] Kitchiner D J. Cardiovascular disease. In: Mclntosh N, Helms PJ, Smyth RL, 6th ed. Forfer \& Arneil's Textbook of Pediatrics. Edinburgh: Churchill Livingstone, 2003; 815-888.

[7] Bloomfield P, Bradbury A, Grubb NR, Newby DE. Cardiovascular Disease. In: Boon NA, Colledge NR, Walker BR, 20th ed. Davidson's Principle and Practice of Medicine. Edinburgh: Churchill Livingstone, 2006; 519-646.

[8] Camm AJ, Bunce NH. Cardiovascular Disease. In: Kumar P, Clark M, 6th ed. Kumar \& Clark Clinical Medicine. Edinburgh: Elsevier Saunders, 2005; 725-872.

[9] Grubb N, Spratt J, Bradbury A. The cardiovascular system. In: Douglas G, Nicol F, Robertson C: Macleod's Clinical Examination.13th ed. London: Charchill Livingstone, 2000; 99-116.

[10] Hoffman JIE, Christianson R. Congenital heart disease in a cohort of 19,502 births with long-tenn follow-up. Am J Cardiol 1978; 42: 641-647.

[11] Nadas AS, Fyler DC, 3rd ed. Pediatric cardiology. Philadelphia: W. B. Saunders Company, 1972.

[12] Hussain M, Hossain M, Amin SK, Molla MR. Pattern of Congenital Heart Disease in Dhaka Shishu Hospital. DS (Child) HJ 1992; 8: 35-46.

[13] Jatav RK, Mamta B. Kumbhare, Srinivas M, Davu Renuka Rao DR, Kumar PG, Reddy PR, Manjusha M. Prevalence and pattern of congenital heart diseases in Karimnagar, Andhra Pradesh, India: diagnosed clinically and by trans-thoracic-twodimensional echocardiography. Int J Res Med Sci. 2014 Feb; 2 (1): 186-192.

[14] Begum NNF Ahmed QS. Pattern of Heart disease among neonates and their outcome: one year experience in noninvasive cardiac laboratory of Combined Military Hospital, Dhaka. Bangladesh J child health2001; 25: 48-52.

[15] Begum NNF, Chowdhury RB, Chowdhury L. Incidence of Congenital Heart Disease among Hospital Live Birth in a Tertiary Hospital of Bangladesh. CVJ 2008; 1 (1): 14-20. 
[16] Rahman S, Ahmed MN, Rahmatullah KHI, Alam MS. The Incidence of Congenital Heart Diseases Diagnosed by NonInvasive Technique. Ten Years Study in Bangladesh. D S (Child) H J 1992; 8: 5-15.

[17] Siddique FM, Kamal SMM, Huq KMHSS. Clinical Presentation of Congenital Heart Disease in hospitalized patients. Bangladesh Heart Journal 1989; 4: 13-17.

[18] Rahman F, Salman M, Akhter N, Patwary SR, Anam K, Rahman MM, Hasan Z, Uddin MJ, Khalil MM, Hafiiz MG, Zaman SM, Fatema N, Rashid MA, Banerjee SK, Haque SS, Chowdhury NA. Pattern of congenital heart diseases. Mymensingh Med J. 2012 Apr; 21 (2): 246-50.

[19] Mitchell S. C., Korones S. B. and Berendes H. W., Congenital heart disease in 56, 109 births. Incidence and natural history. Circulation 43 (1971), pp. 323-332.

[20] Fyler DC, Buckley LP, Hellenbrand WE, Cohn HE. Report of the New England Regional Infant Cardiac Program. Pediatrics, 1980; 65(Suppl): 375-461.

[21] Mollah MAH, Begum NA, Islam MN, Mahrnud RS, Haq MA, Nabar N, Rashid MA. Clinical Profile of Congenital Heart Diseases (CHD): An Analysis of 218 Cases. Bangladesh heart J 2002 July; 17: 62-67.

[22] Rao VS, Reddy R. Profile of congenital heart disease in children. Indian J Pediatr 1974; 41: 244-248.
[23] Hussain M, Tahura S, Hussain MZ, Fatema NN, Razzaque SKA. Pattern of congenital heart disease in Bangladesh: A multi-center study. DS (Child) H J 2011; 27 (1): 5-11.

[24] Vashestha VM, Kalra A, Kalra K, Jain VK. Prevalence of Congenital Heart Disease in School Children. Indian Pediatr. 1993; 30: 1337-1340.

[25] Khalil A, Aggarwal R, Thirupuram S, Arora R. Incidence of Congenital Heart Disease among Hospital Live Births in India. Indian Pediatr. 1994; May; 31 (5) 31: 519-527.

[26] Cameron JW, Rosenthal A, Olsan AD. Malnutrition in hospitalized children with congenital heart disease. Arch Pediatr Adolesc Med. 1995 Oct; 149 (10): 1098-1102.

[27] Hag AI. Pattern of Congenital Heart Disease in Sudanese Children. East Afr Med J 1994 Sep; 71: 580-586.

[28] Begum NNF. Atrial septal defect: Analysis of 393 cases. Chest \& Heart Journal 2003; 27 (1): 31-35.

[29] Keith JD. Ventricular septal defect. In: Keith JD, Rowe RB, Viad P, 3rd ed. Heart disease in Infancy and childhood. Newyork: Mac Millan publishing Co., 1978; 337-350.

[30] Naik S, Tandon R, Gopinath N et al. Tetralogy of Fallot: a clinical profile. Indian Heart J 1972; 24: 14-15. 